\title{
Linking global circulation model outputs to regional geomorphic models: a case study of landslide activity in New Zealand
}

\author{
Michael Schmidt*, Thomas Glade \\ Department of Geography, University of Bonn, Meckenheimer Allee 166, 53115 Bonn, Germany
}

\begin{abstract}
General circulation models (GCMs) were constructed for future projections of circulation patterns on a global scale. IPCC emission scenarios, adopted by GCMs, suggest that climate change is due to anthropogenic emissions of greenhouse gases. Application of GCMs to regionalscale studies is difficult due to the different spatial resolutions. Downscaling techniques transfer GCM results to larger scales. Rainfall-triggered landslides are a worldwide phenomenon and can cause socio-economic problems. Regional models of these geomorphic processes were linked to regionalized GCM outputs for New Zealand. Climate-model outputs from HadCM2SUL were used to produce precipitation and temperature scenarios via analog downscaling. Climate-impact studies have rarely been developed for New Zealand. For both Wellington and Hawke's Bay, climate-change scenarios were applied to 3 deterministic landslide models (the daily rainfall model, the antecedent daily rainfall model and the antecedent soil water status model). All of them relate landslide occurrence to climate conditions. Results give a more reliable projected probability change of landslide occurrence for Wellington than for Hawke's Bay. Wellington's cold-season precipitation is mostly associated with synoptic weather systems depending on large-scale circulation features, captured using the downscaling procedure. In contrast, Hawke's Bay receives its peak precipitation from frequent high-magnitude storms. Common to all 3 applied landslide models for both regions is the trend of decreased landslide activity for the target period, 2070-2099.
\end{abstract}

KEY WORDS: GCM · Climate change impacts · Downscaling • Rainfall-triggered landslides · Threshold models

Resale or republication not permitted without written consent of the publisher

\section{GENERAL CONSIDERATIONS}

Understanding and quantifying climatic changes at a regional scale is one of the most important and uncertain issues within the global-climate-change debate (Giorgi \& Mearns 2002). Currently the best available tools to obtain information on climate changes in the forthcoming century are projections based on ocean-atmosphere coupled general circulation model (GCM) simulations of the climate system as it responds to anthropogenically forced changes (Cubasch et al. 2001). The outcome of a GCM can be enhanced by downscaling techniques to obtain information at a regional scale. However, there are still numerous uncertainties involved. Therefore, the modelling approach presented in this study should be regarded as a first attempt in linking GCM outputs to geomorphic models operating on regional scales.

Based on emission scenarios, the IPCC has described the problems of climate change and global warming as well as the fundamental consequences for our environment and human life. Estimates of the globally averaged temperature rise by 2100 are between 1.4 and $5.8^{\circ} \mathrm{C}$, and the rise in global sea level is projected to be between 9 and $88 \mathrm{~cm}$. The average rate of global warming is probably accelerating the rates of change within the last $10000 \mathrm{yr}$, suggesting that the climate system is in a critical phase, as stated in the third IPCC 
(2001) report. Based on this report it can be assumed that interactions with natural phenomena such as the El Niño Southern Oscillation (ENSO) will occur and also influence socioeconomic conditions (Trenberth 1997). Because the current versions of GCMs are able to simulate the climate vari-

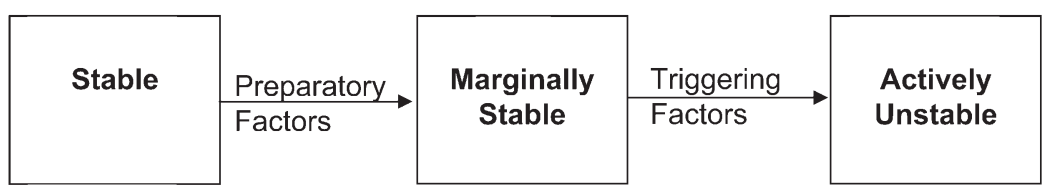

Fig. 1. Concept of progressing conditions influencing landslide initiation (Crozier 1989) ability on a planetary scale, but fail on a local scale, the GCM results can be used as boundary conditions for regional climate studies (Wilby et al. 2000). Regional climate-impact studies are used to investigate the consequences of a changing climate system with respect to potential socio-economic damage. Therefore, the results of regional climate-change studies are not only important for regions with a high potential for destructive events such as floods, hurricanes or droughts (Hulme 2000), but they are also of major importance for regions susceptible to landslide occurrence.

\subsection{Downscaling techniques}

Hewitson \& Crane (1996) categorized downscaling methods as either process-based or empirical. Examples of the first category are dynamical downscaling approaches applying physically based, high-resolution regional climate models with grid-point distances on the order of tenths of a meter nested into a GCM. Nested models are fed with the boundary conditions of the GCM, because regional details can be considered in a physically based approach. Statistical-dynamical downscaling links a regional-scale dynamic model to large-scale information using the frequency distribution of classified weather situations (Frey-Buness et al. 1995). Empirical and statistical downscaling techniques generally use a relationship between a largescale parameter, $G$, and a local parameter, $L$ (Heyen et al. 1996). This approach is based on 3 assumptions: (1) that $G$ is well simulated by the GCM; (2) that most of the regional climate variability is determined by largescale atmospheric conditions; and (3) the relationship between $G$ and $L$ is not influenced by climate change. Long time series of large-scale atmospheric $G$ and local-scale meteorological $(L)$ data can then be used to apply linear or non-linear regression techniques, such as those involving artificial neural networks (Zorita \& von Storch 1999, Wilby et al. 1997). If the time series used to adjust the statistical model to local and regional conditions is long enough (on the order of decades), it is reasonable to assume that it contains many different situations, including more extreme or more probable events in an altered climate (Zorita \& von Storch 1999).
The statistical method introduced by Lorenz (1956, 1969) has been described in recent literature as analog downscaling (e.g. Zorita \& von Storch 1999, Timbal \& McAvaney 2001). A recent review of techniques for regional climate modelling and downscaling was given by Wilby \& Wigley (1997). Zorita \& von Storch (1999) reviewed statistical downscaling methods. At present, statistical downscaling, in particular analog downscaling, performs as well as the more sophisticated methods (Zorita \& von Storch 1999). Advantages are the applicability to normal and non-normal distributed variables, the production of a reliable variability of regional variables (Zorita \& von Storch, 1999), and (purely a technical constraint) model runs may be performed on a regular PC. For this study, analog downscaling is applicable and is consequently applied.

\subsection{Downscaling and climate scenarios in New Zealand}

A general overview of New Zealand's climate is given in Sturman \& Tapper (1996) and Sturman et al. 1999). Basher \& Pittock (1998) reviewed regional climate-change impact studies and their implications. Recent contributions with particular reference to climate-change impacts using GCM outputs were performed by Fowler (1999), who examined the availability of freshwater resources in the Auckland region. Schmidt \& Dehn (2000) analysed links between climate change and landslide activity using GCMs for Wellington, and the methodology they introduced is adopted in this study.

\subsection{Landslides in New Zealand}

Landslides are common phenomena in New Zealand. In some regions, landslides are the most disturbing geomorphic process, with irreversible consequences for nature and humankind. The average annual cost of landslide damage is estimated to total US \$33 million. For the New Zealand economy and society, the direct and indirect damage to public buildings, farm land, infrastructure lines, etc. is substantial (Glade \& Crozier 1996). Thus, landslide occurrences 
are of major concern for New Zealand's governmental authorities, land owners and consultancies.

In this study, the landslide trigger is assumed to be daily precipitation. Other initiating factors, such as earthquakes, fluvial undercutting of slopes and direct human influences (e.g. explosions and engineering works), have been excluded from this study due to the impossibility of linking these factors to GCMs. The basic concept of rainfall-triggered landslides is described in Fig. 1. A slope remains stable until preparatory factors (e.g. weathering and deforestation) transform it into a marginally stable system close to the failure condition. Then, the final trigger results in landslide occurrence.

\subsection{General rainfall threshold models}

Models describing landslide-triggering rainfall conditions are numerous. In general, these models are based on climatic variables, in particular on rainfall, temperature and historical landslide data. Intensive research on landslide-triggering rainfall thresholds started with Caine (1980), who compared precipitation duration and intensity with landslide occurrence. Since then, numerous approaches have been developed (Wieczorek \& Guzzetti 2000), e.g. for the USA by Wilson \& Wieczorek (1995) and Wilson (1997, 2000), for Puerto Rico by Larsen \& Simon (1993), for Japan by Ohmori \& Sugai (1995), for Hong Kong by Premchitt et al. (1994), for Italy by Crosta (1998), Deganutti et al. (2000) and Pollini et al. (1991), for New Zealand by Glade et al. (2001), and for Spain by Corominas \& Moya (1999). Besides the different temporal resolutions of climate and landslide data, periods considered within the models may differ by the quantity measured: rainfall magnitudes over a given time period (e.g. $50 \mathrm{~mm} \mathrm{~h}^{-1}$ in Hong Kong [Premchitt et al. 1994] or $140 \mathrm{~mm} \mathrm{~d}^{-1}$ in Wellington, New Zealand [Glade 2000]), storm totals (e.g. $800 \mathrm{~mm}$ in 3 d during Cyclone Bola in New Zealand; Page et al. 1994), or long-term antecedent conditions (e.g. $1440 \mathrm{~mm} \mathrm{yr}^{-1}$ [Slosson \& Larson 1995] or rainfall above average over some years [Jäger \& Dikau 1994, Glade et al. 2001]).

\subsection{Landslide-triggering rainfall models in New Zealand}

Most models do not compare landslide-triggering rainfall amounts with non-triggering conditionsinformation that is important when applying these models to GCM output data. Additionally, the models are not specifically adapted to New Zealand conditions.
The initial work of Selby (1976), Crozier \& Eyles (1980) and Crozier (1989) on landslide-triggering rainfall conditions was further developed by Glade (1998, 2000) and Glade et al. (2000). These rainfall models include a simple approach comparing daily rainfall with landslide occurrence (daily rainfall model), a more advanced technique coupling daily rainfall and antecedent climatic conditions with landslide failures (antecedent daily rainfall model) and the most sophisticated model considering additionally soil-water conditions (soil water status model). This type of analysis can be applied to other locations.

These 3 models have been adopted in the present work. Their assumptions include

- landslides are triggered by the maximum rainfall within a region, which is associated with minimum potential evapotranspiration;

- all past landslides have been recorded and are included in the landslide inventory;

- remaining boundary conditions (e.g. vegetation coverage, slope stability); and

- no change of the climate system.

As research by Preston \& Crozier (1999) has shown, these assumptions have limitations because the landscape develops and adapts to climate conditions over time. Observations show that landslides are not only triggered by maximum rainfall within a region; however, various studies on distributions of landslides triggered by heavy rainfall events indicate increasing landslide frequency associated with larger rainstorm magnitude (e.g. Australia, Canada, Italy, New Zealand, USA). In addition, due to recording problems, the available landslide information reflects only a fraction of overall landslide occurrence. These limitations have been addressed on a conceptual level, but have not been solved yet (Glade 1998). Nevertheless, within this modelling approach the underlying assumptions are reasonable. This is supported by Crozier (2000), who applied the soil water status model to predict landslide frequency in Wellington.

\subsection{Coupling downscaling techniques and landslide models}

Applications of downscaling techniques from GCMs to landslide activity were first performed by Dehn \& Buma (1999) and Dehn (1999) for the Alvera landslide, located northeast of Cortina d'Ampezzo in Italy. Schmidt \& Dehn (2000) introduced them to New Zealand.

This contribution aims to expand climate-changeimpact studies by linking GCM output to geomorphic models on a regional scale for 2 New Zealand study sites. 


\section{METHODOLOGY}

The overall methodology is given in Fig. 2, which shows the model chain for deriving different scenarios of landslide activity.

\subsection{Data availability}

Two different climatic data sets were available in this study: observed meteorological data from different sources and GCM data from the Hadley Centre's second-generation climate model (Fig. 3). The meteorological data comprise sea-level pressure (SLP), precipitation, temperature, and potential evapotranspiration.

SLP data were supplied by the National Center for Atmospheric Research and compiled by National Center for Atmospheric Prediction global Reanalysis project. These SPL data were up-scaled to a $5 \times 5^{\circ}$ resolution with 1 SLP dataset (noon) per day. The synoptic frame for comparison of different scenes was chosen from the region covering $30-55^{\circ} \mathrm{S}$ and $135^{\circ} \mathrm{E}-175^{\circ} \mathrm{W}$, including the south Australian region, the Tasman Sea and the sea around New Zealand. This operation frame is suitable for observations of the main weather patterns of New Zealand (Kidson \& Tompson 1998, J.W. Kidson pers. commun.). GCM data were extracted from the HadCM2SUL climate model run, based upon the IPCC IS92a emission scenario. For this study, only GCM data for the period of 1950-1970 and 2070-2099 were available.

Daily data for local precipitation of several climate stations in the study regions were extracted from National Institute of Water and Atmosphere database CLIDB. Regional daily maximum values of all stations were calculated for this study. Landslide records are based on a national landslide inventory, compiled by (Glade 1998) and Glade \& Crozier (1996).

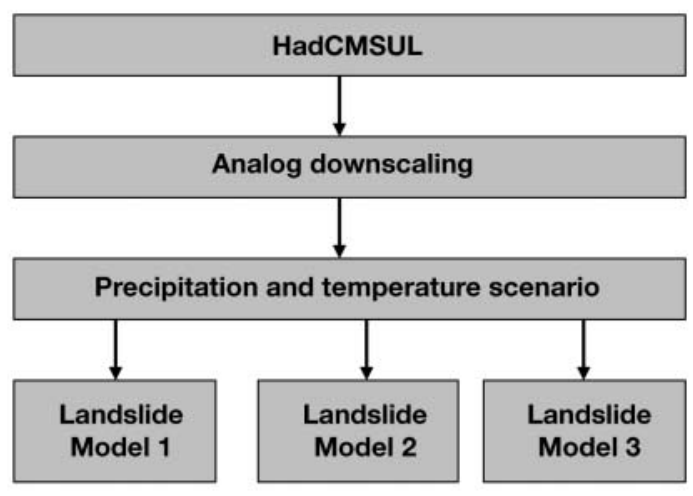

Fig. 2. General methodology

\subsubsection{General circulation model}

The HADCM2 version used in this study has been described by Mitchel \& Johns (1997) and Johns et al. (1997). Both ocean and atmospheric components of the model employ a spatial horizontal grid-point spacing of $3.75^{\circ}$ longitude (approx. $400 \mathrm{~km}$ ) and $2.5^{\circ}$ latitude (approx. $280 \mathrm{~km}$ ). The atmospheric and oceanic models use 19 and 20 vertical layers, respectively. Landsurface processes include vegetation, snow, surface albedo (as a function of vegetation and snow) and a 4layer soil model. Tett et al. (1997) investigated the variability of the surface temperature on a global scale, and over a limited number of regions on a sub-continental scale. They showed that the model reproduced various aspects of the observed global variability and realistically reproduced the ENSO behaviour, which significantly affects the temperature variability over tropical and extra-tropical regions (Giorgi 2002). Johns et al. (1997) concentrated on the validation of the effects of different anthropogenic forces, such as greenhouse gases and the effect of a coupled spin-up process to bring the model to equilibrium. They found that the general circulation pattern was well simulated even though significant errors in the measurement of atmospheric temperature still exist. The observed temperature pattern was better reproduced by the model when sulphate-aerosol effects were included. The global precipitation pattern has been shown to be statistically closer to observed terrestrial pattern than in the former Hadley Centre climate model, in particular, the southern-hemispheric storm tracks were improved (Johns et al. 1997).

This contribution aims to display the potential of linking GCM data to a regional climate-change impact model. In this context the HadCM2SUL was chosen to deliver sufficient input data for the applied downscaling technique.

\subsubsection{Analog downscaling}

The analog method is one of the simplest downscaling schemes (Zorita \& von Storch 1999). This method was initially used for weather forecasting (Lorenz 1969) and short-term climate prediction (Barnett \& Preisendorfer 1978). In this study the relationship between SLP, as large-scale parameter, and local precipitation was investigated.

In order to reduce the noise in a large data set with many degrees of freedom, a standard empirical orthogonal function (EOF) analysis was performed on each of the SLP anomaly patterns: the GCM data set and the Reanalysis data set. The analogs were searched in the space spanned by the leading EOF pattern: 


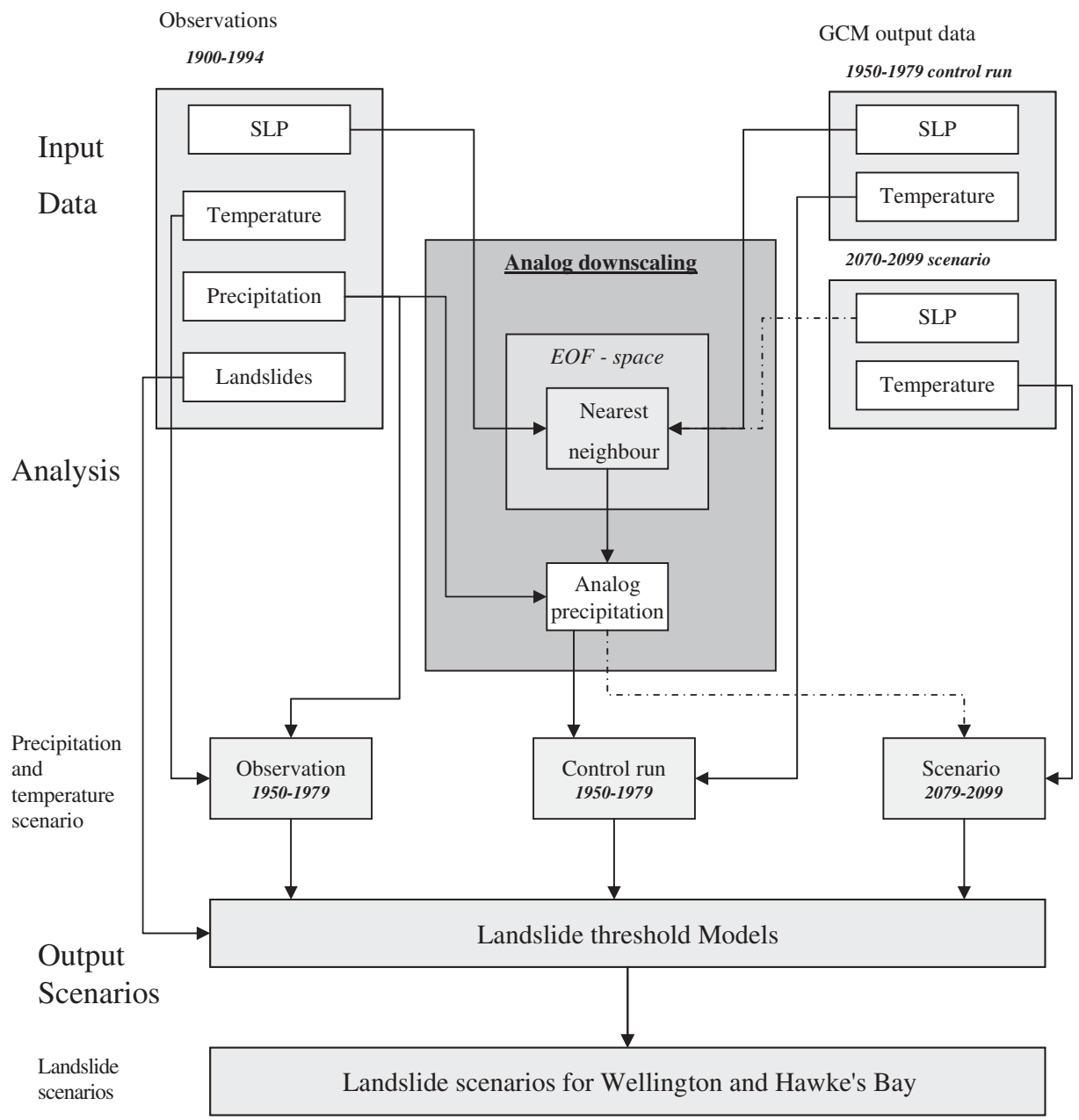

Fig. 3. Method flow chart showing data origin and input, analysis and output scenarios as applied within this study

$$
F(i, t)=\sum_{k=1}^{n} x_{k}(t) g_{k}(i)+\varepsilon(t)
$$

where $i$ is a grid-point index, $t$ represents time, $g_{k}$ is the $k$ th EOF pattern, $x(t)$ is the amplitude of this pattern at time $t, n$ is the number of EOF patterns retained, and $\varepsilon$ is the part of the variability not explained by the $n$th EOF pattern (Zorita \& von Storch 1999). Analogs are searched by minimising the Euclidian metric in the space spanned by the 5 leading EOF patterns. Thus, having found the closest match from the observation records and the GCM SLP pattern, local precipitation data are associated with the corresponding GCM SLP pattern. By applying this method, a local precipitation scenario can be derived from historical data and GCM simulations. Fig. 3 illustrates the analog method and the data sets used in this study.

Analogs were searched in the $20 \mathrm{yr}$ model fit period, 1958-1977. With those analogs stored in a catalogue, the datasets of 2 GCM runs, referred to in the following as the control run (1950-1979) and the scenario (2070-2099), were compared to derive a precipitation scenario. It is possible to pair-wise compare the data sets of the observations and the control run in order to test the downscaling quality or to compare the differences between the control run and the scenario. The spatial variability of temperature as GCM output is low enough to interpolate temperature values directly from the neighbouring grid-points (Dehn \& Buma 1999), while considering the local elevation. Values of precipitation and temperature are used as input parameters for 3 different landslide models.

\subsection{Landslide models}

\subsubsection{Daily rainfall model}

The empirical approach applied within the daily rainfall model is used to get a quick and preliminary 


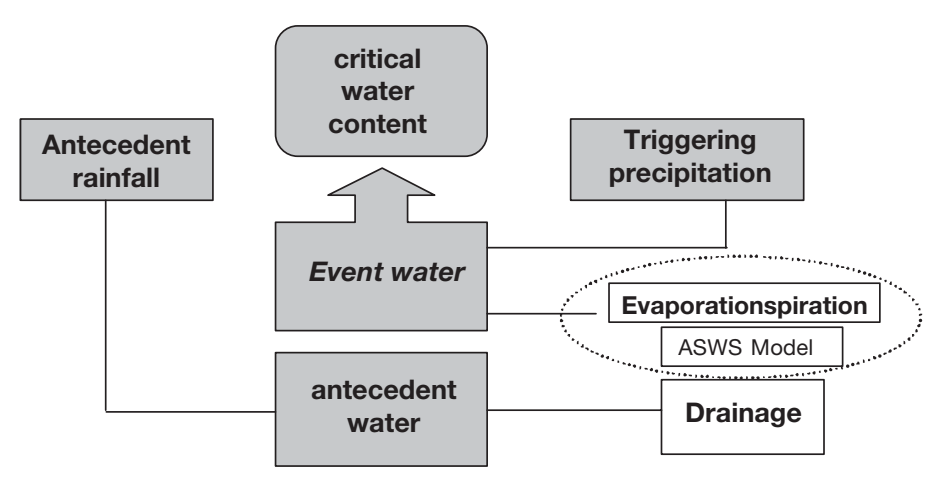

Fig. 4. Concept of landslide-triggering hydroclimatic conditions (modified from Crozier 1989)

overview of precipitation and landslide occurrence for a given region. The numbers of landslide-triggering and non-landslide-triggering rainfall events are divided into $20 \mathrm{~mm}$ classes. The quotient of landslides that have occurred and rain days per class is calculated; this value gives a first indication of the rainfall magnitude necessary for landslide initiation (Glade, 1998).

\subsubsection{Antecedent daily rainfall model}

In this model, antecedent climatic conditions are considered using the model equations based on the concept of critical water content (Crozier \& Eyles 1980). The basic idea of this concept is that water from the rainfall event together with water already in the soil complex can reach a CWC in the slope and result in slope failure due to positive pore-water pressure (Fig. 4).

The rainfall that has occurred previous to a given Day 0 remains in the soil as antecedent water content (AWC). This is expressed in the antecedent daily rainfall index (ADRI). The calculation of the ADRI is based Crozier \& Eyles (1980), modified by Glade (1998):

$$
r_{\mathrm{a}}=r_{1}+2^{k_{\mathrm{d}}} r_{2}+. .+n^{k_{\mathrm{d}}} r_{n}
$$

where $r_{\mathrm{a}}$ is the AWC for Day $0, r_{i}$ the rainfall on the ith day before Day 0 and $n$ the number of days considered before Day $0 . k_{\mathrm{d}}$ is a site-specific empirically derived factor and is given in Table 1 for Wellington and Hawke's Bay. This factor was calculated using stream hydrograph recession curves (Glade 1997). To include the antecedent conditions, a period of $10 \mathrm{~d}$ seemed suitable, because the use of longer AWC conditions showed similar results for these study regions; thus, the soils in the study regions can be classified as highly permeable soils with relatively low water storage capacity (Glade 1998). In order to allow any combinations of $r$ and $r_{a}$ within the $[0,1]$ interval a logistic equation was used (Glade et al. 2000):

$$
\log \left(\frac{p}{1-p}\right)=F\left(r, r_{a}\right)
$$

where $r$ is the daily triggering precipitation and $p$ the probability of landslide occurrence on a given day. The curved envelopes for the different scenarios give the probability of landslide occurrence for a given combination of daily rainfall and antecedent rainfall. For a more detailed description and applications of this model, refer to Glade et al. (2000).

\subsubsection{Antecedent soil water status model (ASWSM)}

Additional to the above-mentioned climatic variables, this model considers soil parameters, such as soil depth, texture, and porosity; thus, it includes waterstorage capacity. Potential evapotranspiration was derived using the Thornthwaite (1948) formula (Glade 2000). Fitzgerald \& Rickard (1960) demonstrated successfully the applicability of Thornthwaite's approach for determining soil-moisture conditions in New Zealand. The method of Toebes (1968) was followed; he applies Thornthwaite's method to calculate daily potential evapotranspiration from temperature data (Glade 2000). These parameters are used to calculate the soil water status index (SWSI). The SWSI is essentially an index of water content based on the climatic water balance. Negative values of the SWSI represent soil storage below field capacity, held in the form of capillary or hygroscopic water. They are expressed as deficit storage and are calculated as follows (Crozier 2000):

$$
D S_{0}=D S_{1}-\left(P_{0}-P E_{0}\right)
$$

where $D S_{0}$ is the deficit water storage on Day 0 (mm), $D S_{1}$ equals the deficit water storage for the day before Day $0(\mathrm{~mm}), P_{0}$ refers to the precipitation on Day 0 $(\mathrm{mm})$, and $P E_{0}$ is the potential evapotranspiration on Day $0(\mathrm{~mm})$. In contrast, positive values are considered to represent gravitational water that accumulates

Table 1. Parameter $k_{\mathrm{d}}$ and equations of derived landslide-triggering rainfall thresholds for the Wellington and Hawke's Bay regions (Glade et al. 2000)

\begin{tabular}{|lcc|}
\hline & $k_{\mathrm{d}}$ & $F\left(r, r_{\mathrm{a}}\right)$ \\
\hline Wellington & -1.52 & $-8.08+0.072 r+0.00036 r_{\mathrm{a}}{ }^{2}$ \\
Hawke's Bay & -1.99 & $-8.82+0.033 r+0.075 r_{\mathrm{a}}-0.00052 r_{\mathrm{a}}{ }^{2}-0.00000012 r_{\mathrm{a}}{ }^{3}$ \\
\hline
\end{tabular}


as groundwater in certain slope locations. They are calculated from rainfall exceeding potential evapotranspiration and soil water storage from the day before Day 0:

$$
E P_{0}=\left(P_{0}-P E_{0}\right)-D S_{1}
$$

where $E P_{0}$ is the excess rainfall on Day $0(\mathrm{~mm})$. The SWSI is constituted by changes in the precipitation, including AWC conditions that have decayed over 10 d. The behaviour of the AWC conditions is given in Eq. (3). Both deficit water storage and excess rainfall are related to landslide occurrence, and they indicate which conditions lead to slope failure with a given probability.

All 3 models use precipitation as climatic input parameter, the ASWSM takes additionally temperature into account. These 2 parameters can be derived from GCM projections via the analog downscaling technique and thus fed into the 3 landslide models in order to estimate future landslide activity.

\subsubsection{Frequency and magnitude analysis}

The change in landslide frequency can be estimated by analysing the projected occurrence time intervals of CWC, defined by Crozier (1998) as the sum of AWC and the event water content (EWC):

$$
\mathrm{CWC}=\mathrm{AWC}+\mathrm{EWC}
$$

where EWC is the precipitation of a given day, and AWC equals the CWC of the preceding day. The probabilities of CWC occurrence were thus calculated for different return periods for the 3 model runs. The return periods are: daily (P1), $10 \mathrm{~d}$ (P10), monthly (P30) and a complete season (P90). Following this approach, different data sets from actual observations, the control run and the scenario were compared.

\section{ENVIRONMENTAL SETTINGS OF STUDY REGIONS}

Both study regions-Wellington and Hawke's Bay-are located on the North Island of New Zealand (Fig. 5). Wellington is greatly influenced by a westerly weather pattern of frontal origin. The observed catchment extends approximately $30 \mathrm{~km}^{2}$, with an average annual precipitation of $1250 \mathrm{~mm}$. The hilly sector in the NE part of the Wellington region is steeply dissected by valleys, mostly following geologic fault lines. The mean uplift rate has been about $1 \mathrm{~mm} \mathrm{yr}^{-1}$ during the last 1 Myr. Argillites and greywacke underlie yellow-brown loamy soils. The native vegetation was dense native forest, which

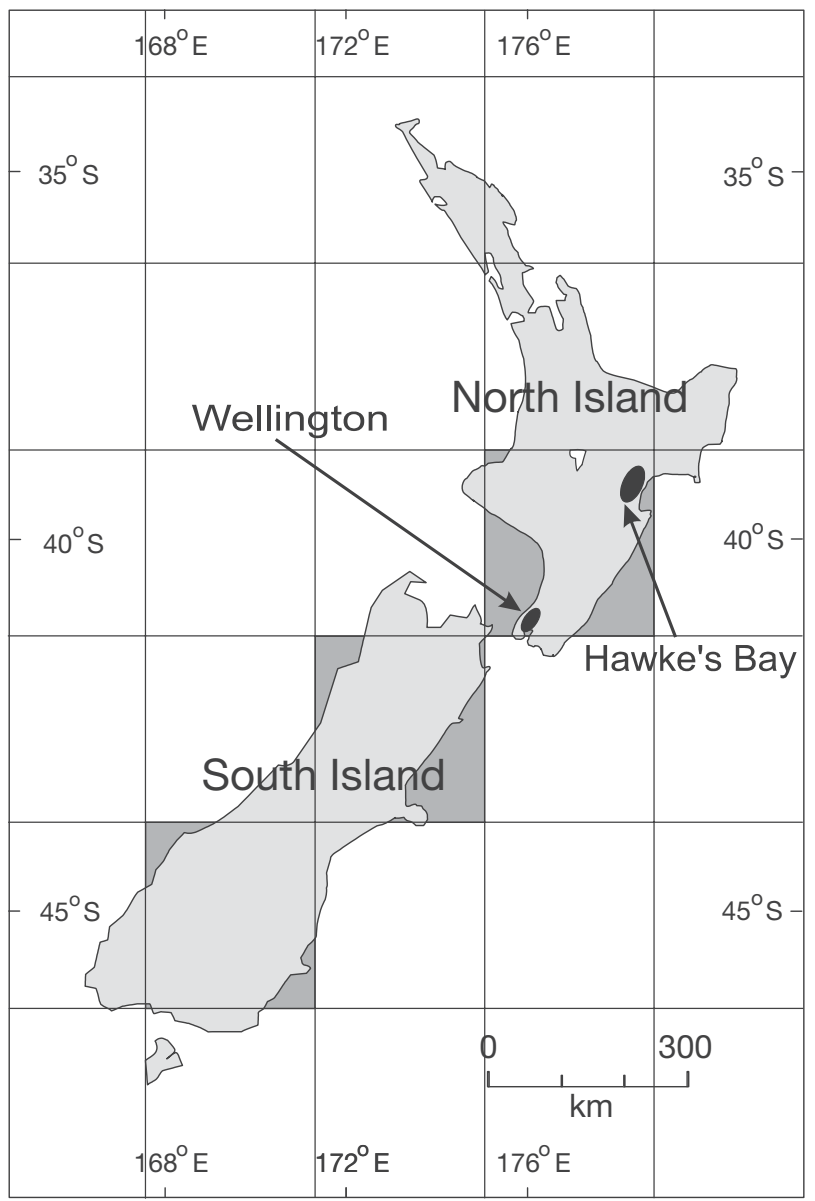

Fig. 5. Approximate location of the study regions in New Zealand. The boxes show the HadCM2 Grid resolution $\left(2.5^{\circ} \times\right.$ $\left.3.75^{\circ}\right)$. The grey boxes represent land mass in the GCM

was converted into pasture for sheep farming during the last few decades of the nineteenth century. Since the 1970s, scrub has occupied the pasture areas. Within the last $20 \mathrm{yr}$, the area has become progressively more suburban.

The second $49 \mathrm{~km}^{2}$ catchment Lake Tutira is located in Hawke's Bay. Westerly and easterly weather conditions contribute two-thirds of the average annual precipitation (approx. $1400 \mathrm{~mm}$ ). Of major concern for landslide failures are the high-precipitation events, often resulting from weakening tropical cyclones moving down the east coast of New Zealand. Accompanying these cyclones are high short-term precipitation events, e.g. Cyclone Bola, which led to a rainfall total of $800 \mathrm{~mm}$ over $3 \mathrm{~d}$ (9-11 March) in 1988. Steep relief as a result of highly eroded terrain is characteristic for this region. Silt- and sandstones are covered with soils consisting predominantly of volcanic ashes from Mt. Ruapehu eruptions. The uplift of the whole region has been approximately $2 \mathrm{~mm} \mathrm{yr}^{-1}$ since the 
Kaikoura Orogeny (Pleistocene). Similar to the Wellington region, vegetation changed dramatically from native forest to pasture with the arrival of European settlers, around 1850-1870. Currently, land use is changing gradually from pasture to plantations of pine forests.

Soils are well developed under natural vegetation in both study regions, as is the case in most parts of the North Island. After European settlement and transformation of native forest to pasture for sheep farming, numerous landslides occurred following high-precipitation events (Fig. 6). As Page et al. (1994) and Glade \& Crozier (1996) have shown for Hawke's Bay and Wellington, respectively, these landslides consist mostly of shallow soil and debris slides and flows. The majority of the failures have occurred within the last century, and this indicates the high level of human interference through land-use change (Goff 1997, Page \& Trustrum 1997).

New Zealand as a whole is represented in the GCM model by a few grid cells only (Fig. 5). Although it is evident that this is too coarse to model climatic parameters with high spatial variability in the complex and dissected terrain of New Zealand's hill country (Kidson \& Tompson 1998, Fowler 1999, Schmidt \& Dehn 2000), no practical alternatives are available. Therefore, this GCM model was applied to model geomorphic responses, and particularly landslide behaviour.

\section{RESULTS}

Downscaled GCM precipitation data are available as input data to the landslide models (Schmidt \& Dehn 2000). Correlations for the seasonal mean precipitation with the coefficient from observed and calculated precipitation data were only acceptable for the southern hemispheric winter (JJA), with 0.57 for Wellington and 0.59 for Hawke's Bay (Table 2). Consequently, all further conclusions are drawn for the winter season only. In Wellington, most precipitation falls during winter $(40 \%)$. In addition, historical data show that most of the landslides occur in the same period (Glade 1998).

Table 2. Correlations $r$ of observed and calculated seasonal precipitation for Wellington and Hawke's Bay, 1958-1977

\begin{tabular}{|lrrrr|}
\hline & MAM & JJA & SON & DJF \\
\hline Wellington & -0.03 & 0.57 & 0.09 & -0.26 \\
Hawke's Bay & 0.25 & 0.59 & 0.07 & 0.02 \\
\hline
\end{tabular}

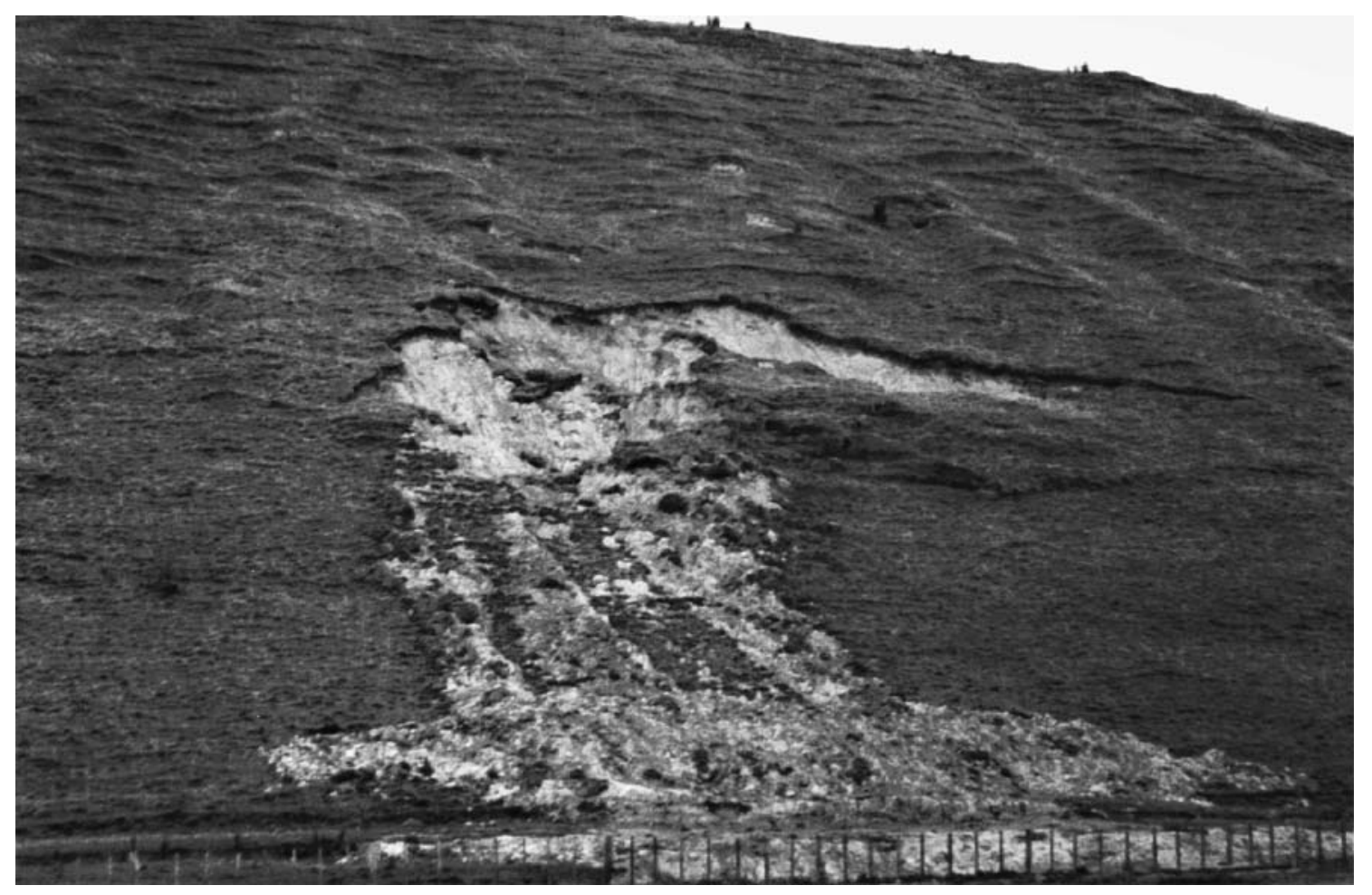

Fig. 6. Shallow debris slide and flow, North Island of New Zealand (Photograph: M. Schmidt, 1999) 
Table 3. Monthly means of winter precipitation (JJA; in mm) for Wellington and Hawke's Bay

\begin{tabular}{|lccc|}
\hline & $\begin{array}{c}\text { Observations } \\
(1950-1979)\end{array}$ & $\begin{array}{c}\text { Control run } \\
(1950-1979)\end{array}$ & $\begin{array}{c}\text { Scenario } \\
(2070-2099)\end{array}$ \\
\hline Wellington & 218.4 & 213.3 & 187.1 \\
Hawke's Bay & 347.9 & 316.3 & 278.6 \\
\hline
\end{tabular}

Table 4. Mean $( \pm \mathrm{SD})$ daily precipitation (in $\mathrm{mm}$ ) of the 3 model runs for the winter season

\begin{tabular}{|lrrr|}
\hline & $\begin{array}{c}\text { Observations } \\
(1950-1979)\end{array}$ & $\begin{array}{r}\text { Control run } \\
(1950-1979)\end{array}$ & $\begin{array}{c}\text { Scenario } \\
(2070-2099)\end{array}$ \\
\hline Wellington & $7.3 \pm 12.8$ & $7.4 \pm 12.6$ & $6.4 \pm 10.7$ \\
Hawke's Bay & $11.7 \pm 21.7$ & $11.0 \pm 21.0$ & $9.6 \pm 16.9$ \\
\hline
\end{tabular}

\subsection{Rainfall scenarios}

Three precipitation datasets were compared. Table 3 lists the calculations for seasonal precipitation. The model seems to work well on this scale $(<2.5 \%$ deviation between observations and the control run for Wellington; $<10 \%$ for Hawke's Bay).

The results for the daily precipitation values for the winter season show similarities, but for Wellington the daily mean precipitation is higher in the control run than in the observations (Table 4). In Hawke's Bay both means and SD are larger, which indicates the higher variability of rainfall events there. Tables 3 \& 4 indicate a projected decrease in precipitation in the scenarios.

\subsection{Landslide models}

\subsubsection{Daily rainfall model}

Climate input data to the daily rainfall model include the observations, the control run and finally the scenario. The number of landslides in the study area for 1950-1979 were compared with precipitation events and given quotients for each class (Fig. 7).

The percentages of landslides per precipitation class show, in both regions, that below a precipitation amount of $20 \mathrm{~mm}$ (minimum probability threshold) landslides have never occurred during historic times. The class containing precipitation which always triggered landslides in the past is represented as the $100 \%$ landslide probability threshold in Fig. 7.

The model is suitable for Wellington. Comparing the observations and the control run, a decrease in heavy precipitation events is visible, and thus a reduction of landslide events is projected. For Hawke's Bay the model represents well the lower precipitation classes. For the classes below $120 \mathrm{~mm}$ it can be assumed that the precipitation has an advective origin, so the control run describes the observation values satisfactory. However, a slight tendency for fewer days with high precipitation values is visible. Above $120 \mathrm{~mm}$ another signal may be included, probably originating from frequently occurring storm events. These heavy precipitation events are not well modelled in the control run, which is not surprising, because they are extreme events and these singularities are not easy to model in a GCM. Despite this limitation, the scenario does not appear to have fewer of these extreme events. The general trend in both regions is projected by this model for 2079-2099 and suggests a trend to decreased landslide activity.

This rather simple model already gives some insight into the system. The major drawback is that the antecedent climatic conditions are not taken into account. Therefore, antecedent rainfall is considered in the following models as a preparatory factor for slope failure (Crozier 1989).

\subsubsection{Antecedent daily rainfall model}

Probabilities of landslide occurrence including the antecedent rainfall conditions as preparatory factors and the actual rainfall as triggering event were calculated. The analysis is based on calculations using the equations from Table 1. The model results are shown in Fig. 8.

The points underneath the probability curves represent the landslide probabilities as calculated with the ADRI. Comparing the number of landslide events in the control run with observations demonstrates that the ADRI and the number of landslide events are well modelled (Fig. 9a,b). For the higher probability classes $(>0.5)$ the model underestimates the observations slightly. The scenario shows a tendency for less landslide activity in the future. The modelling results for Hawke's Bay are also acceptable. Higher classes are slightly over-represented in the control run. The scenario supports the apparent decrease in observed landslide events. Common to both figures is the projection of a decrease in landslide activity, especially for Hawke's Bay.

Even if this model takes the antecedent rainfall conditions into account, temperature is of great influence, but the soil water storage capacity is still not considered. The following landslide-model addresses this limitation. 

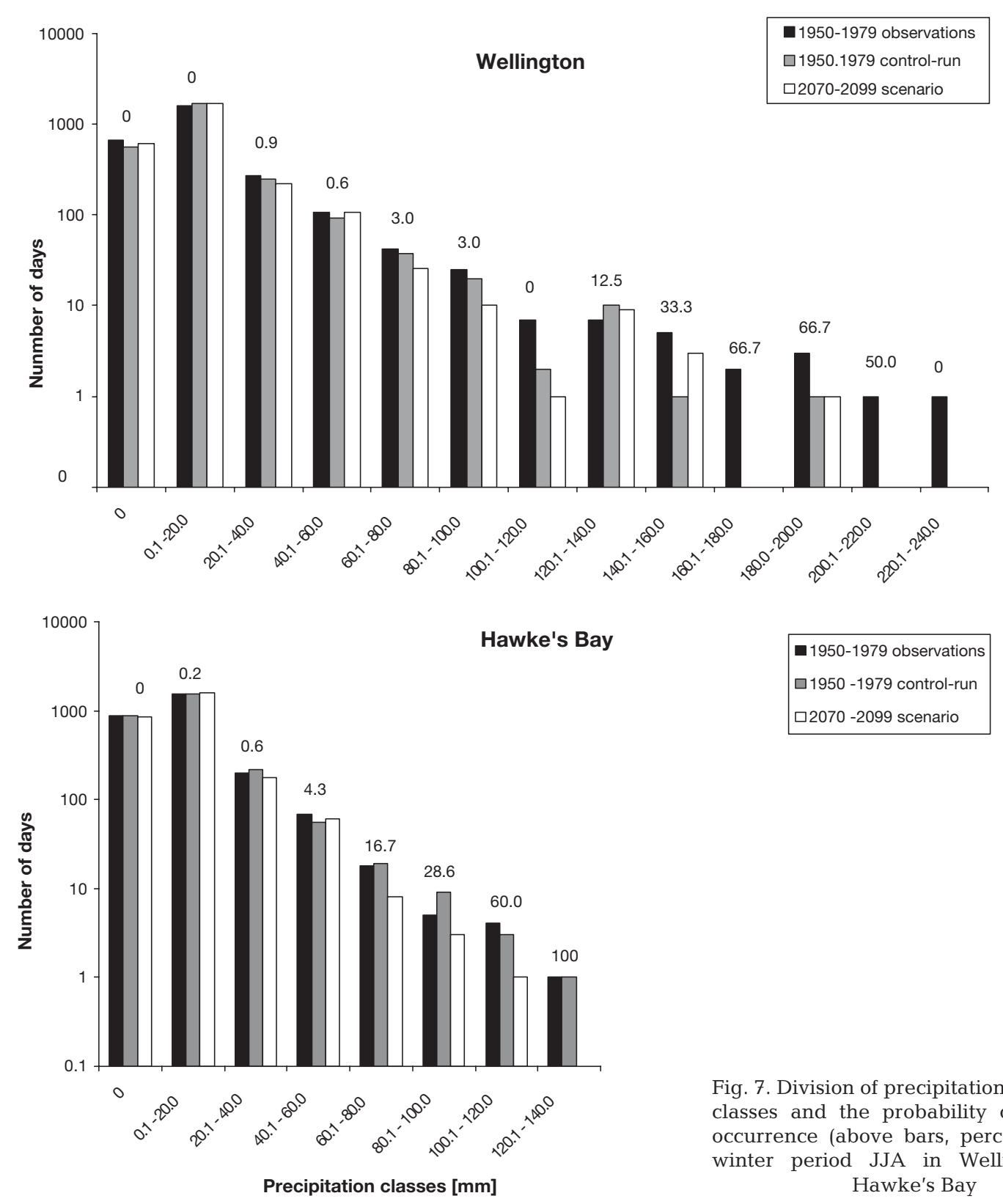

Fig. 7. Division of precipitation into $20 \mathrm{~mm}$ classes and the probability of landslide occurrence (above bars, percent) for the winter period JJA in Wellington and Hawke's Bay

\subsubsection{Soil water status model}

Soil water storage characteristics are taken from Glade (2000). Average soil moisture capacities were calculated for Hawke's Bay and Wellington to be 46.4 and $71.4 \mathrm{~mm}$, respectively. These values were used to calculate regional scenarios. The model output of SWSI is displayed versus precipitation in Fig. 10. In the figure, the $0 \%$ threshold line describes the rainfall value below which landslides have never occurred, and the $100 \%$ envelope represents the amount of rainfall above which landslides always have occurred in the past. These thresholds are then, again under the assumption of remaining side conditions, used to express the climate-driven change in landslide activity, by projection of the values from the rainfall scenario to similar scales (Fig. 10c,f).

Triggering precipitation values and days with probable landslide occurrence are marked in Fig. 10a,d. The probable landslides cannot be dated exactly to either the day of occurrence or the following day due to the unknown measurement times of the historical precipitation records. For example, the recorded daily precipitation on Day 1 refers to the period from 09:00 $\mathrm{h}$ on Day 0 to 09:00 h on Day 1, while the landslide might have occurred at 23:00 $\mathrm{h}$ on Day 1 , thus the 
Wellington
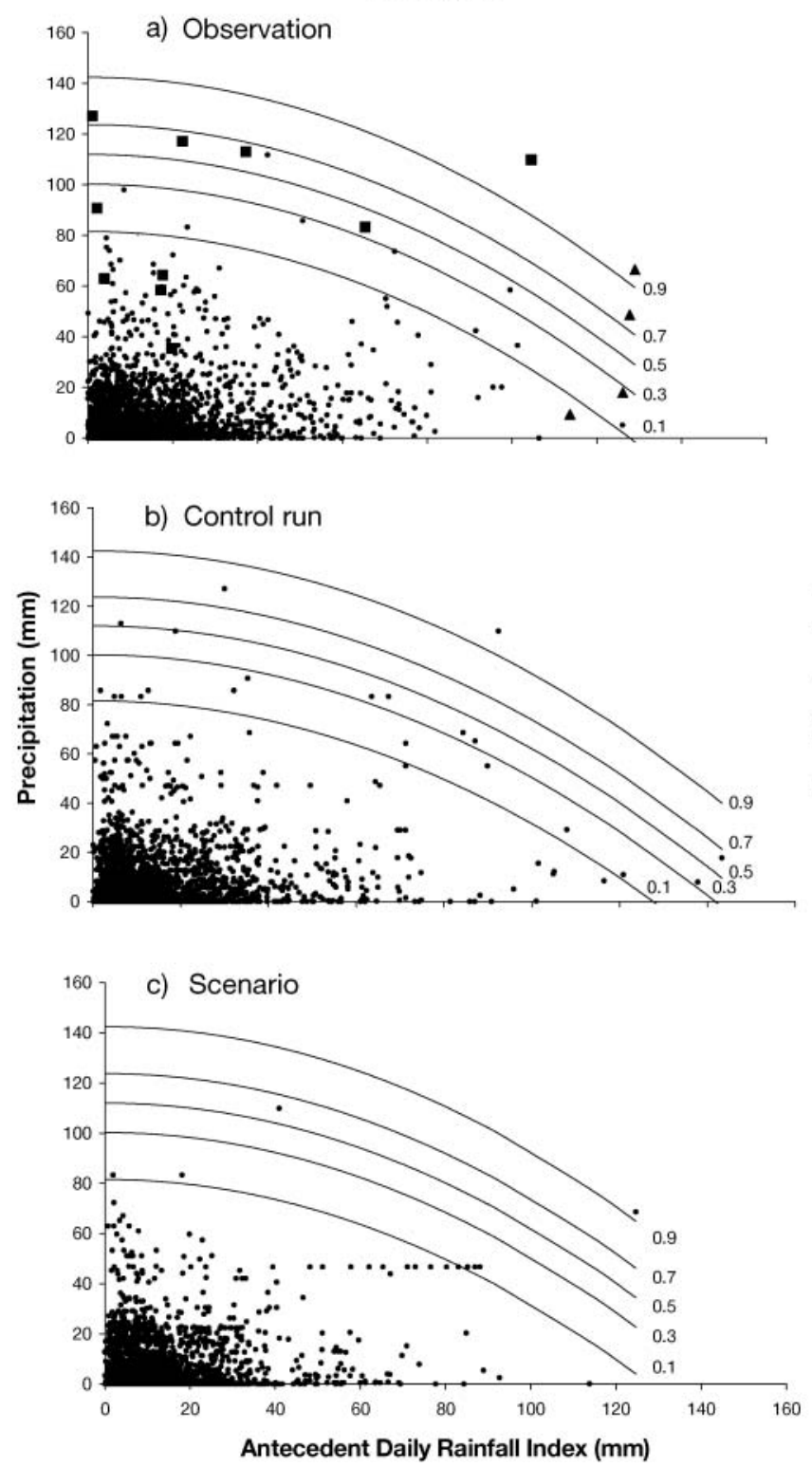

Hawke's Bay
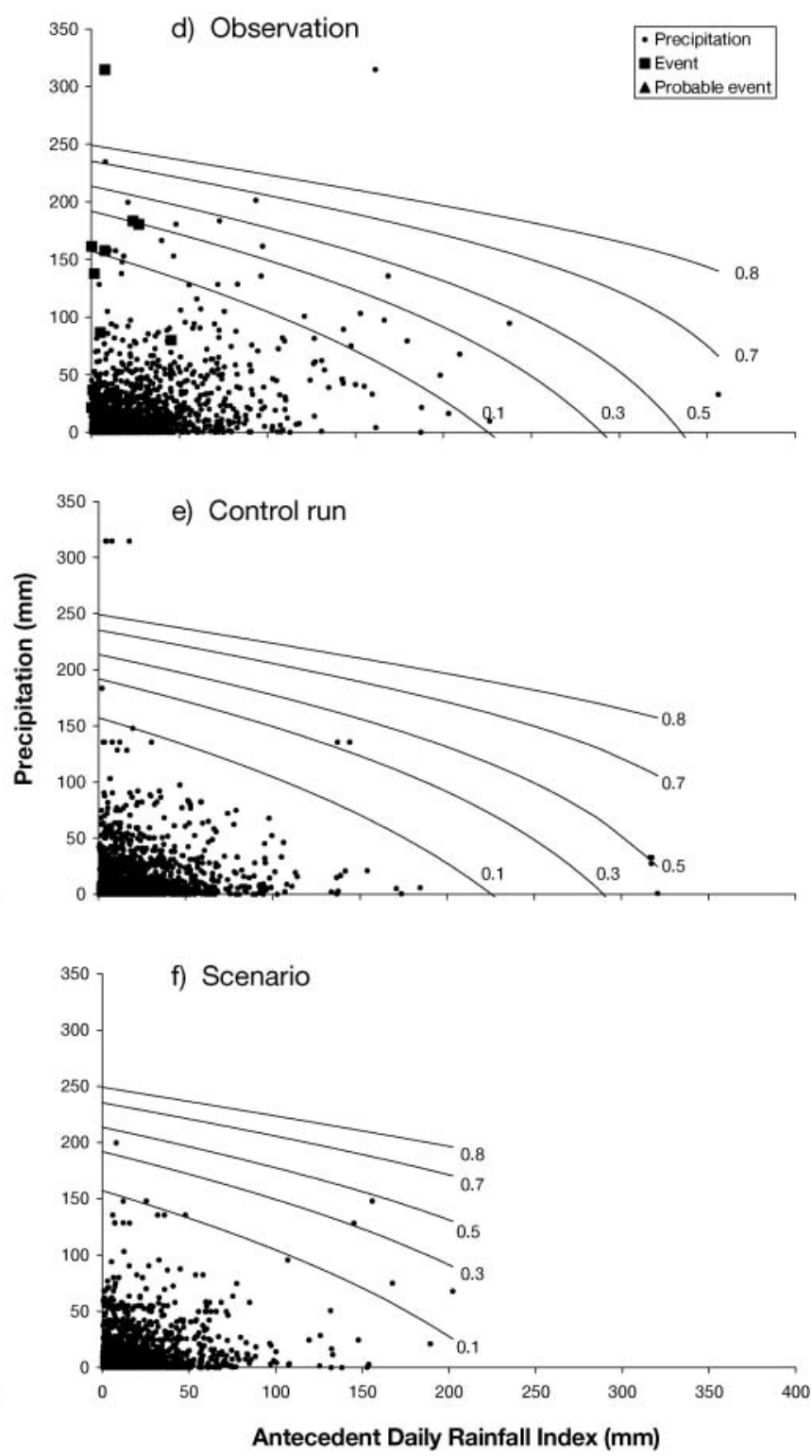

Fig. 8. Relation between daily precipitation and the calculated antecedent daily rainfall index (ADRI) for Wellington (a-c) and Hawke's Bay $(d-f)$. Curved lines are the modelled probability lines for landslide occurrence for the observations $(a, d)$, the control run $(b, e)$ and the scenario $(c, f)$

rainfall of Day 2 should also have been taken into account (Glade 1997). However, this is a general problem which cannot be solved here. Nevertheless, the event distribution given in Fig. 10b (control run) shows a good reproduction of the observed data. The scenario (Fig. 10c) projects fewer events with high landslide probability. Comparing Fig. 10d,e there are fewer events with SWSI $>25 \%$ modelled. It can be concluded that the model is not yet applicable to these classes.

The model results are summarised in Fig. 11. Comparing the model runs of observations and the control run for Wellington, there is a constant underestimation for all probability classes as a consequence of a probable model bias. But the general application seems to work well. The scenario projects a general trend for lower landslide activity.

It seems for Hawke's Bay that more events of medium landslide probability are simulated from the control run than actually observed. In addition, very extreme events are not captured. This might be due to very high threshold values in Hawke's Bay (Fig. 10d-f), resulting from heavy rainstorms and weakening tropical cyclones. 

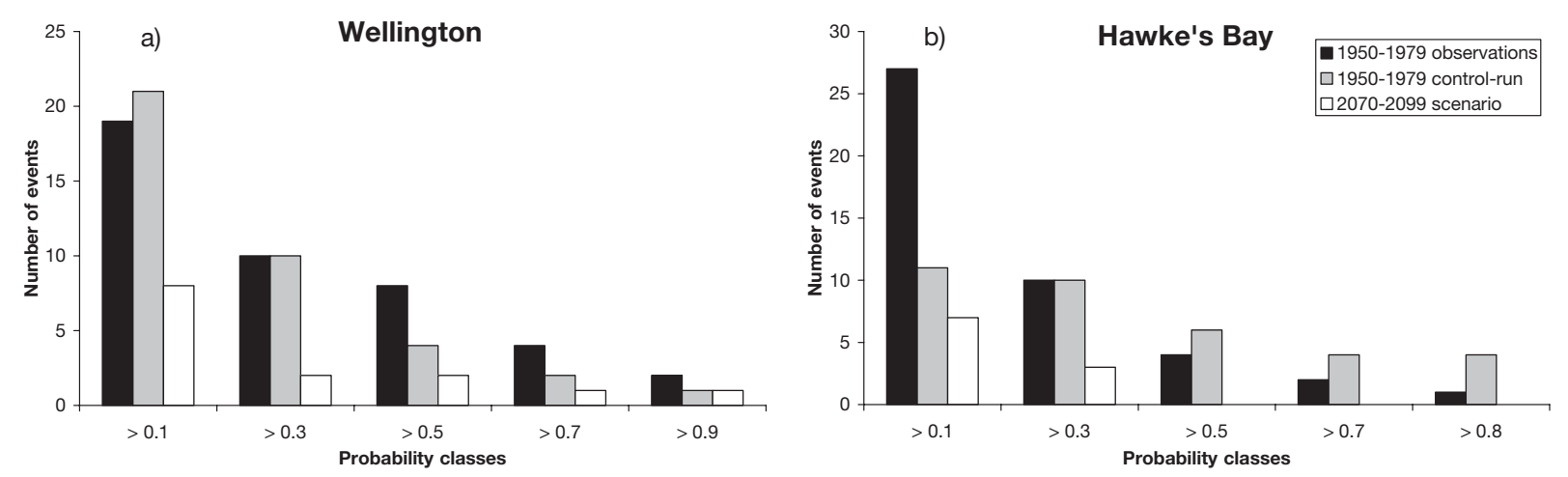

Fig. 9. Summary of ADRI calculations classed in 5 probability classes for different model runs

\section{Wellington}
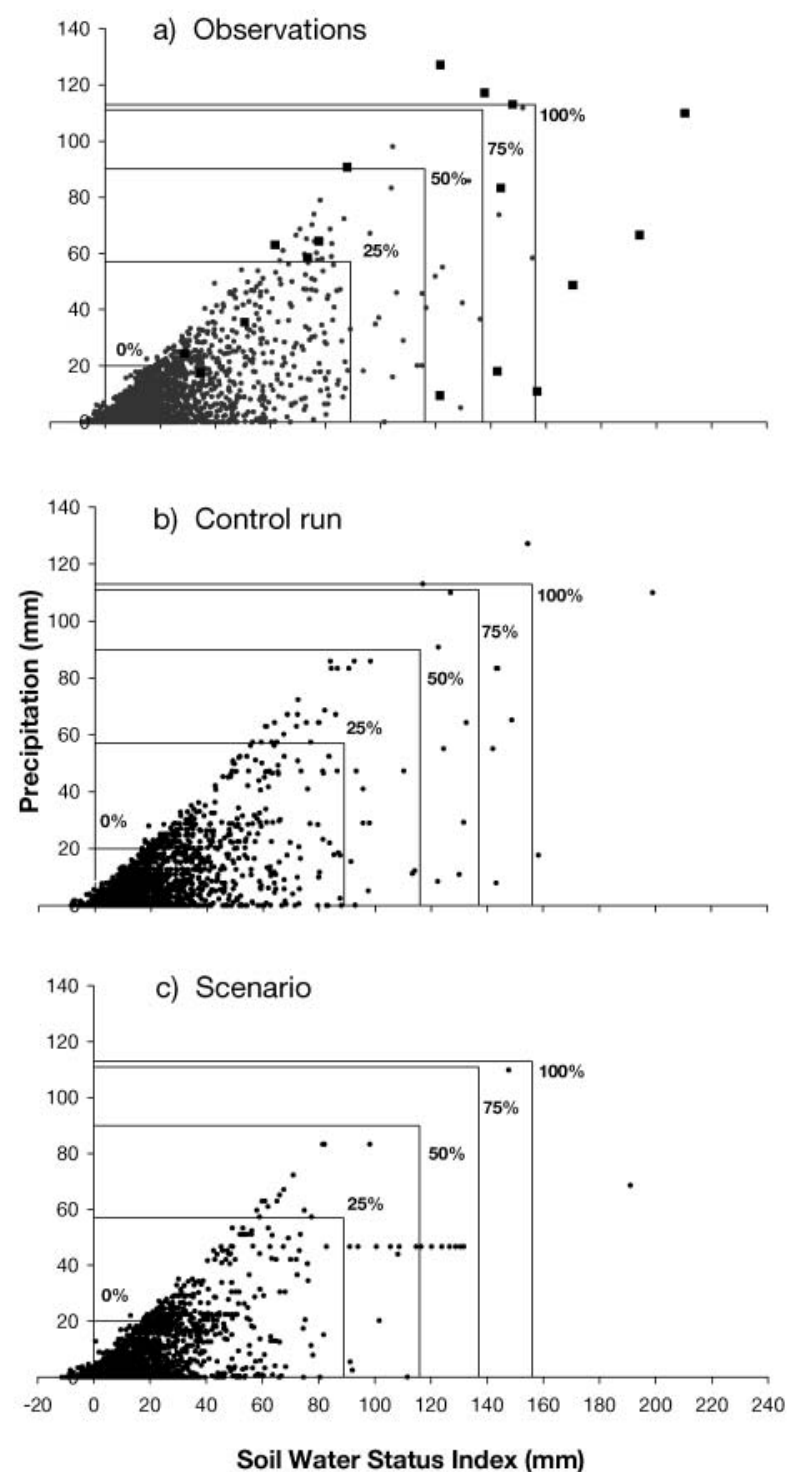

\section{Hawke's Bay}
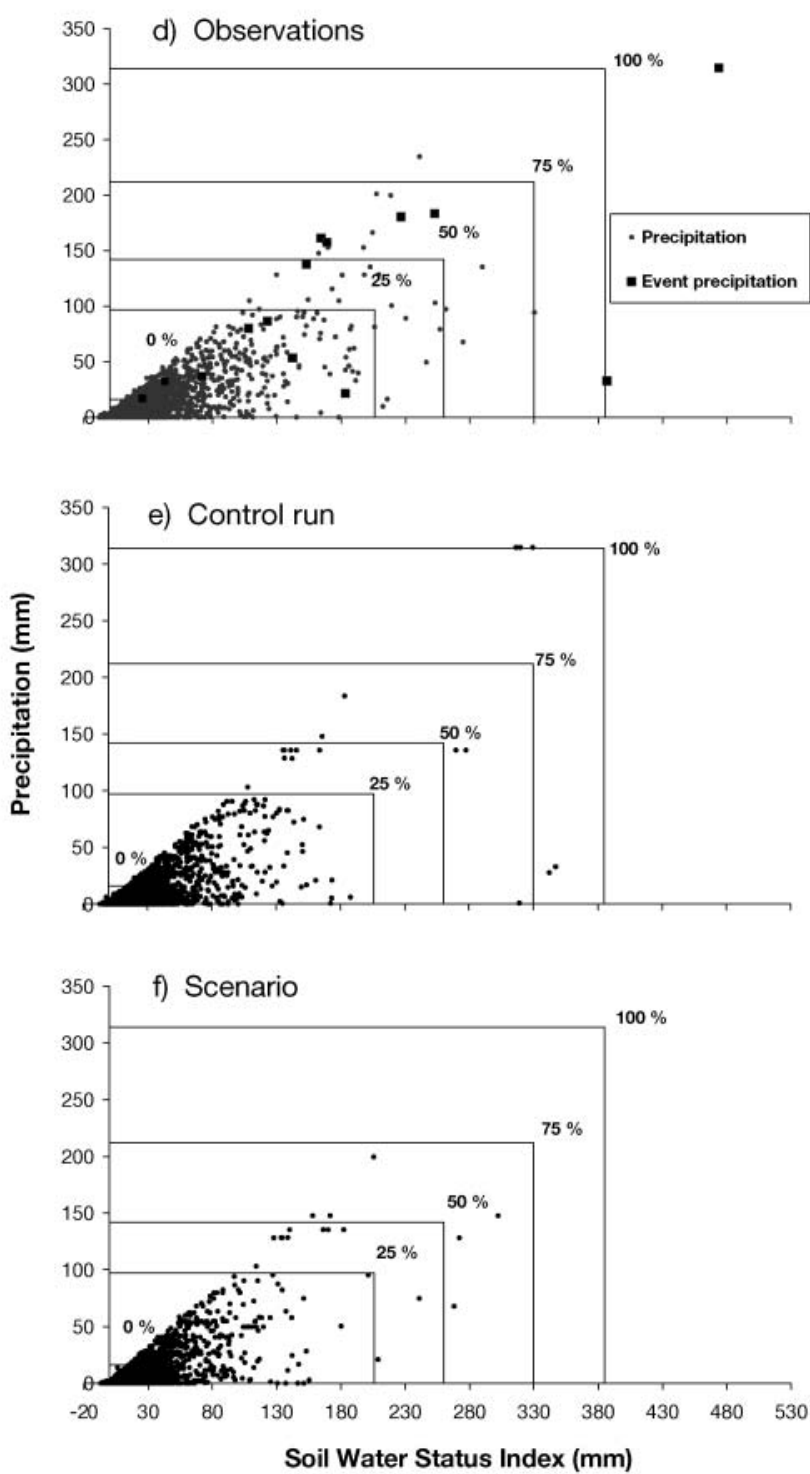

Fig. 10. The soil water status model. Displayed is the daily precipitation and the calculated soil water status index (SWSI) for observations (1950-1979; a,d), the control run (1950-1979; b,e) and the scenario (2070-2099; c,f). In addition, the probability boundaries of $0,25,50,75$ and $100 \%$ probability of landslide occurrence are shown 

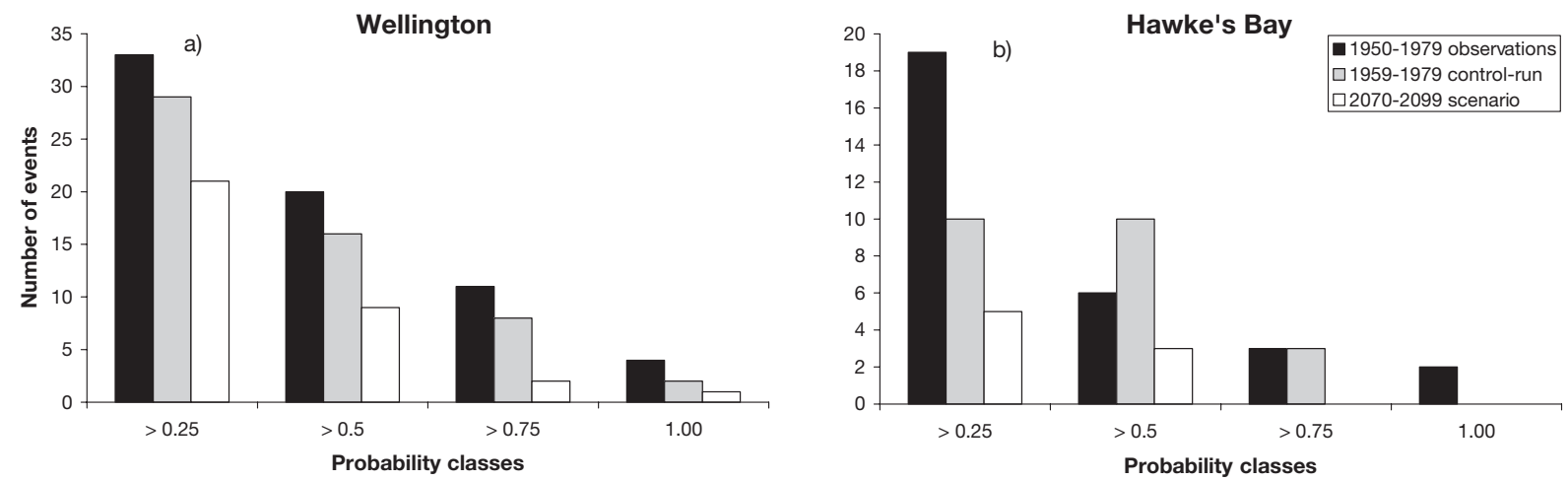

Fig. 11. Summary of SWSI calculations for the 3 different model runs

\subsubsection{Frequency and magnitude}

For a comprehensive landslide assessment, the return periods of events with high damage potential are important (IPCC 2001). To observe the probability that the CWC will reoccur in 1,10d, 30d and $90 \mathrm{~d}$, calculations were performed for both study sites for the observations, the control run and the scenario. Results for CWC are given in Fig. 12. For Wellington the CWC value of $220 \mathrm{~mm}$ (50\% of landslide occurrence) has a probability of 0.3 to occur within a $90 \mathrm{~d}$ interval (1 winter). The same result is displayed in the control run. In comparison, the scenario projects a probability of less than 0.1 in $90 \mathrm{~d}$.

The observations compared with the control run show good results for Wellington, where the mean values do not differ significantly. But a significant reduction of $16 \%$ from the control run to the scenario is also projected. For Hawke's Bay the control run data differ from the observations by $8 \%$ with a reduction of $10 \%$ for the scenario. These results may be attributed to the better model quality for Wellington; however, there might be a general trend towards reduced landslide activity for the scenario period.

\section{DISCUSSION AND CONCLUSIONS}

The analog downscaling approach produces precipitation scenarios that are realistic for both study sites. It would be necessary for a detailed interpretation of the landslide scenarios to compare ensemble runs using several AOGCM outputs. Uncertainties, especially on a regional scale, are very high by the use of only 1 GCM. Projection results have to be examined carefully and any interpretations have to be regarded as general trends only.

The emission scenario IS92 was used in the climate model. More recent scenarios were established by the IPCC, with different assumptions of greenhouse-gas emissions (http://www.grida.no/climate/ipcc/emission/ index.htm). GCM runs with different underlying emission scenarios will also result in different outcomes and should be considered in interpretations. Nevertheless, the use of only 1 AOGCM is justified, because it can be demonstrated that the general methodology is applicable and produces landslide scenarios that are related to reality. The model chain can easily be adapted to other GCM model outputs for regions where landslide and climate data are also available.

A systematic feature of this approach is obvious in Figs. 8c \& 10c through the projection of similar precipitation values. The conclusion is either that the training period of $20 \mathrm{yr}$ was not long enough to produce enough different SLP patterns or that certain synoptic situations will occur more frequently in the projected future. This needs to be investigated further.

Despite all limitations, climate scenarios appear to be useful as input parameters for geomorphological process modelling. To a first approximation, the daily rainfall model gives a preliminary overview of climate and landslide conditions. Improvements were reached, in particular for Wellington, using the antecedent daily rainfall model and the soil water status model. Latter models give reasonable results comparing the observations and the control run.

Comparing Wellington and Hawke's Bay, the most important difference is the amount of total precipitation required to trigger landslides (Fig. 10). In Hawke's Bay heavy precipitation events are mostly responsible for landslide initiation. In contrast, antecedent rainfall raises the pore water pressure over several days and leads to slope failure in Wellington. Due to the fact that heavy rainfall events cannot be modelled properly, the model for Hawke's Bay does not work as well as that for the Wellington region. However, there is a general tendency in both study sites towards a reduced number of landslide events associated with a high probability of rainfall occurrence (Fig. 11). 


\section{Wellington}

a) Observations

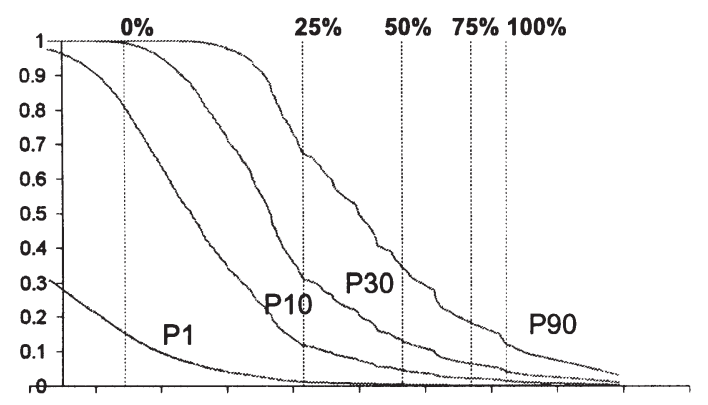

b) Control run

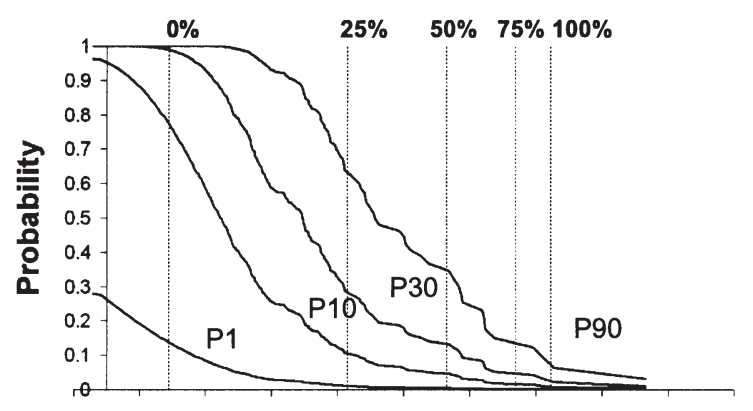

c) Scenario

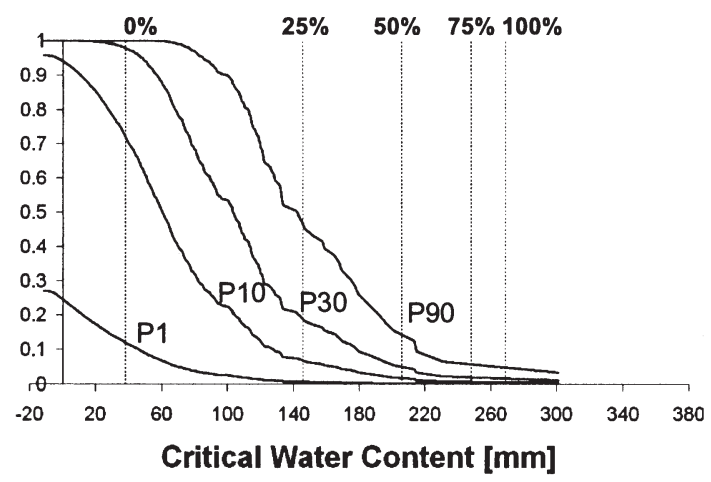

Hawke's Bay

d) Observations

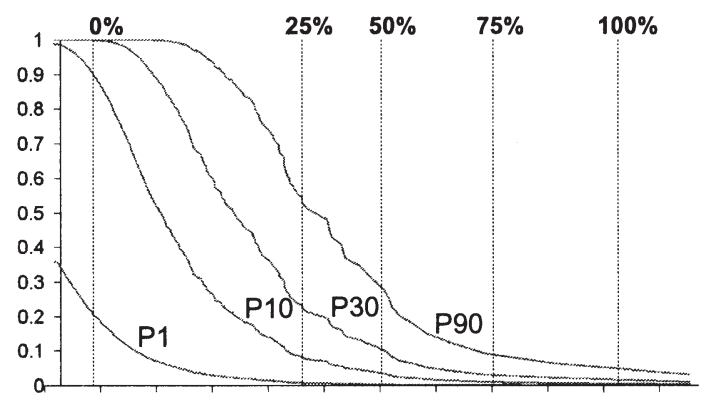

e) Control run

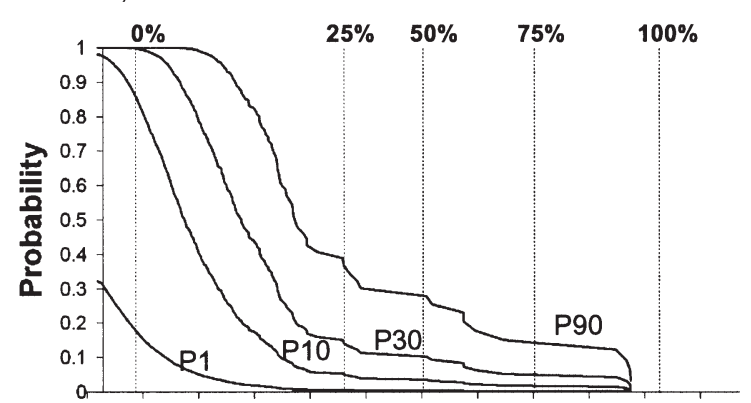

f) Scenario

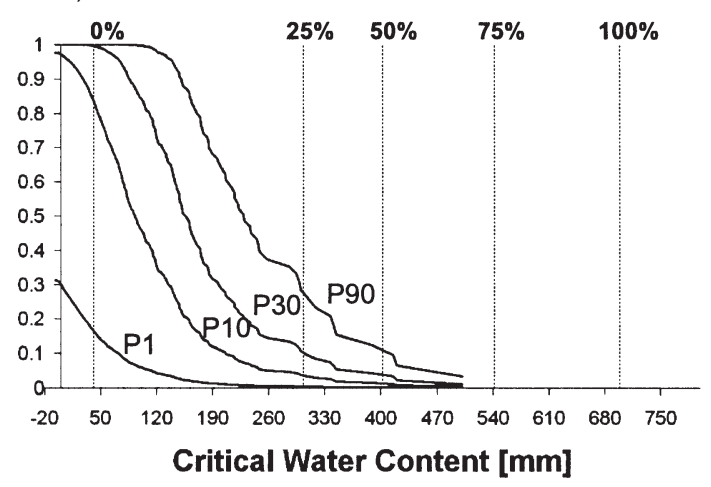

Fig. 12. The probability of the critical water content (CWC) to occur is given for 1, 10, 30 and $90 \mathrm{~d}$ return periods for Wellington $(\mathrm{a}-\mathrm{c})$ and Hawke's Bay $(\mathrm{d}-\mathrm{f})$ and for observations (1950-1979; a,d), the control run (1950-1979; b,e) and the scenario (2070-2099; $\mathrm{C}, \mathrm{f})$. In addition, the probability boundaries of $0,25,50,75$ and $100 \%$ probability of landslide occurrence are shown

One limitation within this landslide model approach is that neither landslide magnitudes nor landslide types can be considered separately. A strong assumption is also the remaining conditions under a changing climate, e.g. the unchanged relationship between SLP and precipitation as well as the unchanged triggering thresholds. This modelling approach should be seen as a first attempt to link GCM outputs to geomorphic models operating on regional scales. Based on the results of this study, there are several areas for future research into the coupling of more and better
GCMs, potentially with other downscaling techniques to produce the most reliable scenario for precipitation and landslides.

Landslide models have to be developed to provide results by both landslide type and landslide magnitude. Specific and detailed climate conditions should be attributed to single landslide failures rather than assigning regional climate maxima to landslide occurrence, allowing more detailed regional landslide-triggering climate analysis. Potentially, the landslide models could be coupled to economic mod- 
els in order to calculate probable damages and, hence, help decision makers to evaluate long-term cost functions and give implications for preventive actions.

Acknowledgements. M. Dehn, supported by E. Zorita and H. von Storch at the GKSS in Geesthacht, Germany, contributed significantly to the downscaling methodology as to the data mining. Many thanks to N. Preston for improving the manuscript. The reviewers gave helpful comments and improved the manuscript.

\section{LITERATURE CITED}

Barnett TP, Preisendorfer RW (1978) Multifield analog prediction of short-term climate fluctuations using a climate state vector. J Atmos Sci 35:1771-1787

Basher RE, Pittock AE (1998) Australasia. In: Watson RT, Zinyowera MC, Moss RH, Dokken DJ (eds) The regional impacts of climate change. IPCC Special Report Working Group II, Cambridge University Press, Cambridge, p 105-149

Caine N (1980) The rainfall intensity-duration control of shallow landslides and debris flows. Geogr Ann A 62:23-27

Corominas J, Moya J (1999) Reconstructing recent landslide activity in relation to rainfall in the Llobregat River basin, Eastern Pyrenees, Spain. Geomorphology 30:79-93

Crosta G (1998) Regionalization of rainfall thresholds: an aid to landslide hazard evaluation. Environ Geol 35:131-145

Crozier MJ (1989) Landslides: causes, consequences and environment. Croom Helm, London

Crozier MJ (1997) The climate-landslide couple: a southern hemisphere perspective. In: Matthews JA, Brunsden D, Frenzel B, Gläser B, Weiß MM (eds) Rapid mass movement as a source of climatic evidence for the holocene, Vol 19. Gustav Fischer, Stuttgart, p 333-354

Crozier MJ (2000) Prediction of rainfall-triggerd landslides: a test of the Antecedent Water Status Model. Earth Surf Process Landf 24:825-833

Crozier MJ, Eyles RJ (1980) Assessing the probability of rapid mass movement. In: Proc 3rd Australia \& New Zealand conference on geomechanics. New Zealand Institute of Engineers, Proceedings of Technical Groups 6: p 247-251

Crozier MJ, Glade T (1999) Frequency and magnitude of landsliding: fundamental research issues. Z Geomorphol NF Suppl 115:141-155

Cubasch U, Meehl GA, Boer GJ, Stouffer RJ, Dix M, Noda A, Senior CA, Raper S, Yap Y (2001) Projections of future climate change. In: Houghton JT et al (eds) Climate change, 2001, The scientific basis. Contribution of Working Group I to the Third Assessment Report of the Intergovernmental Panel on Climate Change. Cambridge University Press, Cambridge, p 267-289

Deganutti AM, Marchi L, Arattano M (2000) Rainfall and debris-flow occurrence in the Moscardo basin (Italian Alps). In: Wieczorek GF, Naeser ND (eds) Debris-flow hazards mitigation: mechanics, prediction, and assessment, 16-18 August 2000. AA Balkema, Taipei, p 67-72

Dehn M (1999) Application of an analog downscaling technique to the assessment of future landslide activity - a case study in the Italian Alps. Clim Res 13:103-113

Dehn M, Buma J (1999) Modelling future landslide activity based on general circulation models. Geomorphology 30: 175-187
Fowler A (1999) Potential climate change impacts on water resources in the Auckland Region (New Zealand). Clim Res 11:221-245

Frey-Buness A, Heimann D, Sausen R (1995) A statisticaldynamical downscaling procedure for global climate simulations. Theor Appl Climatol 5:117-131

Giorgi F, Mearns LO (2002) Calculation of average, uncertainty range, and reliability of regional climate changes from AOGCM simulations via the 'reliability ensemble averaging' (REA) method. J Clim 15:1141-1158

Glade T (1998) Establishing the frequency and magnitude of landslide-triggering rainstorm events in New Zealand. Environ Geol 35:160-174

Glade T (2000) Modelling landslide triggering rainfall thresholds at a range of complexities. In: Bromhead E, Dixon N, Ibsen ML (eds) Landslides in research, theory and practice, Vol 2. Thomas Telford, Kingston University, UK, p 633-640

Glade T, Crozier M (1996) Towards a national landslide information base for New Zealand. NZ Geogr 52:29-40

Glade T, Crozier MJ, Smith P (2000) Applying probability determination to refine landslide-triggering rainfall thresholds using an empirical 'Antecedent Daily Rainfall Model'. Pure Appl Geophys 157:1059-1079

Glade T, Kadereit A, Dikau R (2001) Landslides at the Tertiary escarpment of Rheinhessen, southwest Germany. Z Geomorphol Suppl 125:65-92

Goff JR (1997) A chronology of natural and anthropogenic influences on coastal sedimentation, New Zealand. Mar Geol 138:105-117

Hewitson BC, Crane RG (1996) Climate downscaling: techniques and application. Clim Res 7:85-95

Heyen H, Zorita E, von Storch H (1996) Statistical downscaling of monthly mean North Atlantic air-pressure to sea level anomalies in the Balic Sea. Tellus 48:312-323

Hulme M (2000) Global warming. Prog Phys Geogr 4:591-599

IPCC (2001) Climate change 2001: impacts, adaption and vulnerability - contribution of Working Group II to the Third Assessment Report. Cambridge University Press, Cambridge

Jäger S, Dikau R (1994) The temporal occurrence of landslides in South Germany. In: Casale R, Fantechi R, Flageollet JC (eds) Temporal occurrence and forecasting of landslides in the European Community. European Community, Brussels, p 509-564

Johns TC, Carnell RE, Crossley JF, Gregory JM, Mitchell FB, Senior CA, Tett FB, Wood RA (1997) The second Hadley Centre coupled ocean-atmosphere GCM. Clim Dyn 13:103-134

Kidson JW, Tompson CS (1998) A comparison of statistical and model-based downscaling techniques for estimating local climate variations. J Clim 11:735-753

Larsen MC, Simon A (1993) A rainfall intensity-duration threshold for landslides in a humid-tropical environment, Puerto Rico. Geog Ann Ser A 75:13-23

Lorenz EN (1956) Empirical orthogonal functions and statistical weather prediction. Scientific Report 1, Statistical Forecasting Project, Massachusetts Institute of Technology, Cambridge, MA

Lorenz EN (1969) Atmospheric predictability as revealed by naturally occurring analogs. J Atmos Sci 26:636-646

Mitchell JFB, Johns TC (1997) On modification of global warming by sulfate aerosols. J Clim 10:245-267

Ohmori H, Sugai T (1995) Toward geomorphometric models for estimating landslide dynamics and forecasting landslide occurrence in Japanese mountains. Z Geomorphol 101:149-164 
Page MJ, Trustrum NA (1997) A late Holocene lake sediment record of the erosion response to land use change in a steep land catchment, New Zealand. Z Geomorphol 41: 369-392

Page MJ, Trustrum NA, Dymond JR (1994) Sediment budget to assess the geomorphic effect of a cyclonic storm, New Zealand. Geomorphology 9:169-188

Pollini G, Ceriani M, Lauzi S, Padovan N, Crosta G (1991) Rainfall and soil slipping in Valtellina. In: Bell DH (ed) Landslides. Proc 6th Int Symp, Christchurch, 10-14 February 1992. AA Balkema, Rotterdam, p 183-188

Premchitt J, Brand EW, Chen PYM (1994) Rain-induced landslides in Hong Kong. Asia Eng 6:43-51

Preston N, Crozier MJ (1999) Resistance to shallow landslide failure through root-derived cohesion in East Coast hill country soils, North Islands, New Zealand. Earth Surf Process Landf 24:665-675

Schmidt M, Dehn M (2000) Examining links between climate change and landslide activity using GCMs: case studies from Italy and New Zealand. In: McLaren S, Kniveton D (eds) Linking climate change to land surface change. Kluwer Academic Publishers, Dordrecht, p 123-141

Selby MJ (1976) Slope erosion due to extreme rainfall: a case study from New Zealand. Geog Ann Ser A 58:131-138

Slosson JE, Larson RA (1995) Slope failures in Southern California: rainfall thresholds, prediction, and human causes. Environ Eng Geosci 1:393-401

Sturman A, Tapper NJ (1996) The weather and climate of Australia and New Zealand. Oxford University Press, Melbourne

Sturman AP, McGowan HA, Sproken-Smith RA (1999) Mesoscale and local climates in New Zealand. Prog Phys Geogr 23:611-635

Tett FB, Johns TC, Mitchell FB (1997) Global and regional variability in a coupled AOGCM. Clim Dyn 13:303-323

Thornthwaite CW (1948) An approach towards a rational classification of climate. Geog Rev 38:55-96

Editorial responsibility: Chris de Freitas, Auckland, New Zealand
Timbal B, McAvaney BJ (2001) An analoge-based method to downscale surface air temperature: application for Australia. Clim Dyn 17:947-963

Toebes C (1968) Computation of the potential evapotranspiration by the Thornthwaite method. In: Handbook of Hydrological procedures: procedure no. 14. Water and Soil Division, Ministry of Works, Wellington, NZ

Trenberth KE (1997) The use and abuse of climate models. Nature 386:131-133

Wieczorek GF, Guzzetti F (2000) A review of rainfall thresholds for triggering landslides. Mediterranean storms. In: Proc EGS Plinius Conference, Maratea, Italy, October 1999. p 407-414

Wilby RL, Wigley TML (1997) Downscaling general circulation model output: a review of methods and limitations. Prog Phys Geogr 21:530-548

Wilby RL, Hay LE, Leemans R (2000) A comparison of downscaled and raw GCM output: implications for climate change scenarios in the San Juan River Basin, Colorado. J Hydrol 225:67-91

Wilson RC (1997) Normalizing rainfall/debris-flow thresholds along the U.S. Pacific Coast for long-term variations in precipitation climate. In: Chen CL (ed) Proceedings, first international conference on debris-flow hazards mitigation: mechanics, prediction, and assessment, 7-9 August 1997. Hydraulics Division, American Society of Civil Engineers, San Francisco, CA, p 32-43

Wilson RC (2000) Climatic variations in rainfall thresholds for debris-flow activity. Mediterranean storms. In: Proc EGS Plinius Conference, Maratea, Italy, October 1999, p 415-424

Wilson RC, Wieczorek, GF (1995) Rainfall thresholds for the initiation of debris flows at La Honda, California. Environ Eng Geosci 1:11-27

Zorita E, von Storch H (1999) The analog method as a simple statistical downscaling technique: comparison with more complicated methods. J Clim 12:2474-2489

Submitted: November 28, 2001; Accepted: September 4, 2003 Proofs received from author(s): December 2, 2003 